\title{
Study of the Road Surface Technologies
}

\author{
${ }^{1}$ Oleg G. Novoselov, ${ }^{2}$ Yuliya V. Saifullina, ${ }^{3}$ Farida F. Ismagilova \\ ${ }^{1-3}$ Kazan Federal University, Naberezhnye Chelny Branch \\ Email: OlGNovoselov@kpfu.ru,JVSajfullina@kpfu.ru,Farida--93@mail.ru
}

\section{Received: 20 ${ }^{\text {th }}$ August 2019, Accepted: $30^{\text {th }}$ September 2019, Published: $31^{\text {st }}$ October 2019}

\begin{abstract}
The work is devoted to the study of the influence of automobile roads and walkways surface conditions on the public consciousness. The formation of certain qualities in a person, and their reflection in reality were investigated. The main method of the research was the group survey, as well as the personal interview, in which the association method was used. As a result of the study, the influence of the degree of destruction and deformation of the road surface on the emotional state of a person was defined. At the same time, the work has revealed a certain relationship in the reduction of quality of human capital and the road conditions. The acquisition of information for further research is also very important.
\end{abstract}

\section{Keywords}

Deformation, Road Surface, Destruction, Human Consciousness, Human Capital.

\section{Introduction}

One of the most important factors, shaping the human consciousness is the surrounding reality, which is diverse and multi-faceted. A lot of research was devoted to the influence on human consciousness of such issues as: family, relationships of others, mass media, personal desires, biological factors, natural environment, and so on [1-6]. The authors in this work deal with the question of the influence of road conditions on the consciousness of a person, as an individual, and also on the society as a whole. In this paper, the consciousness will be considered from the side of dialectical materialism. So, the consciousness is a subjective reality, which exists in the mind of a person, in his perceptions, imaginations, thoughts, as a reflection of objective reality.

A person can associate any road, highway, driveway to home with his own life path. During the life, a person can have various situations, difficulties, obstacles, the need to make difficult decisions, dead ends, and vice versa a good and easy life, direct path. The aim of the work is to correlate various life situations with road defects, namely how they are sank in the mind and to what extent.

The prerequisite for the beginning of this study was the popular wisdom - the proverbs and sayings (catch phrases), in other words - phraseological units. Phraseologisms can be considered as the reflections of life situations and their influence on human consciousness. The following phraseological units are associated with the road conditions:

1. "Our life is like a one-way road, and it is important not to miss your turn, because there will be no going back". Winston Churchill [7];

2. "A person with a clear purpose will advance even on the worst road. A person without any goal will not advance even in the smoothest". Thomas Carlyle [8];

3. "The height charms us, the steps to it do not: with the summit in our eye, we love to walk along the plain". Johann Wolfgang Goethe [9];

4. It is a long lane that has no turning [10].

Directly or indirectly, phraseological units draw a parallel between the road and the life path. Let's consider each of them separately. The author of the first phrase is Winston Churchill. He compares the life path with the road, and gives some characteristics, typical only to it (traffic arrangement). In the phrase number two and proverbs number four, there are the parallels with geometric characteristics of the road, namely length, rise and descent. The phrase of Thomas Carlyle draws an analogy between the living a life without a goal and a hard road, as well as the living with a goal and driving along a smooth road. In this statement, the measure of comparison is the "smooth road", just one of the criteria for assessment the condition of the road surface and the purpose of our study.

\section{Methods}

Two types of surveys were developed for this study. Both surveys consist of six questions, in which it is proposed to look at the picture and choose the most suitable answer (or write it yourself). The same question was asked in each of the six survey points, namely, "What do you feel, when you look at the picture". Each point consisted of a road image and possible answers, briefly describing the emotions of the respondent: positive emotions, negative emotions, no emotions, alternative reply (this variant is given for the purpose if the respondent wants to give his own answer). The difference between the surveys is that in the first survey there are the images and photographs of the road surface with various defects and demolitions (Fig. 1), namely with the single cracks, network of cracks, pothole, crumbling of road edges, breaches, ruts. And the second survey also consists of road surface images, but without obvious defects - the road surface is in good condition. 


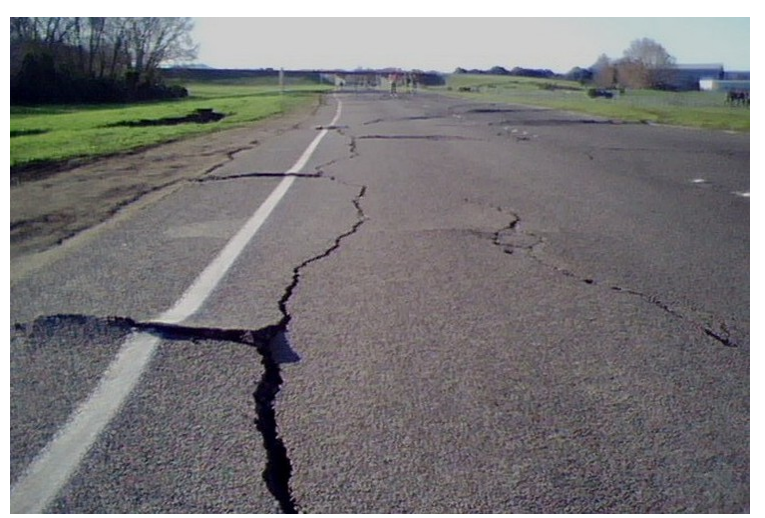

a

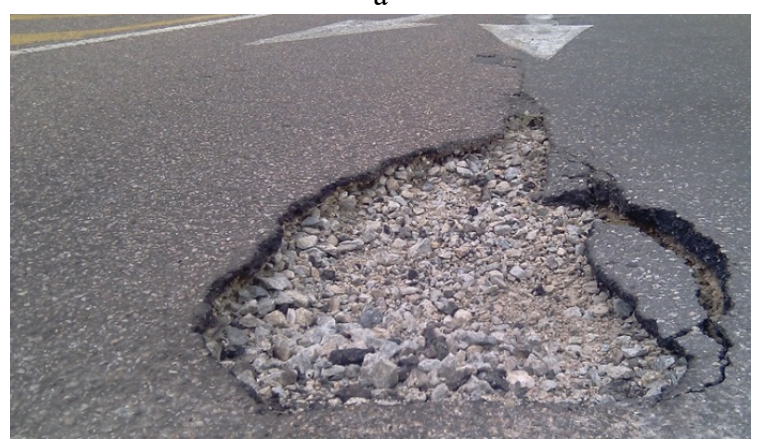

c

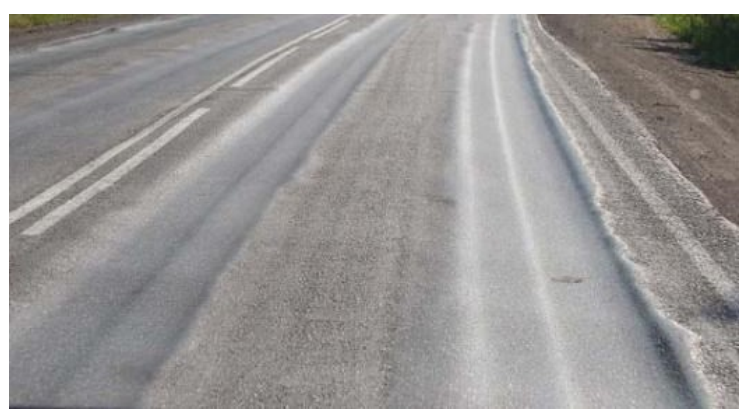

e

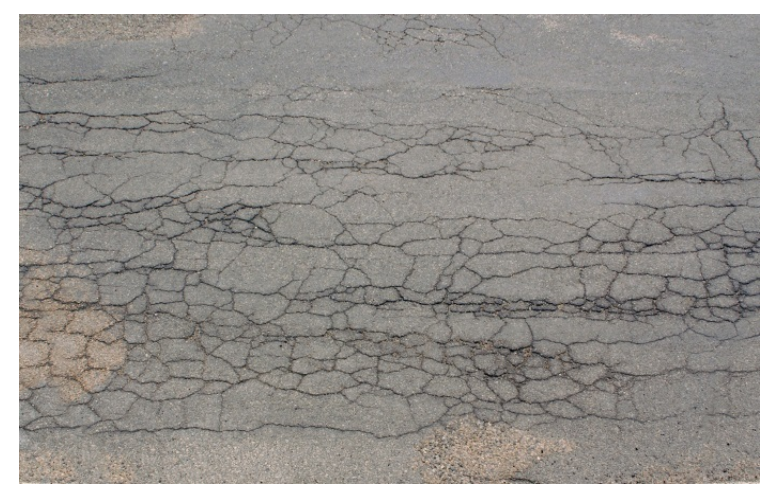

b

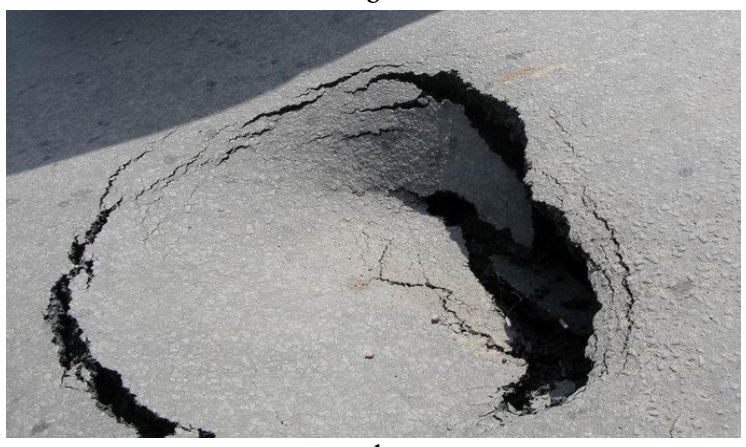

d

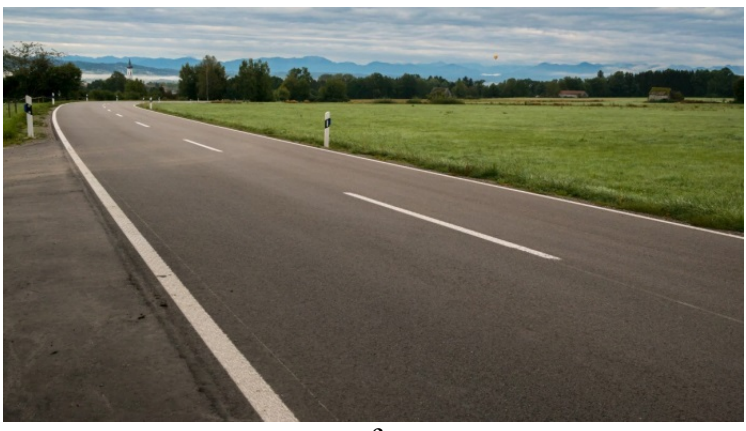

f

Figure 1: The State of Road Surface.

a: Single Cracks, b: Network of Cracks, c: Pothole, d: Breach, e: Rut, f: Road Surface in "Good" Condition.

The asphalt concrete roads are shown in all pictures, because this material is one of the most common coatings for automobile roads and walkways.

All people, who wanted to answer the survey questions, were divided into 2 groups. Only one type of survey was given to each group, without the possibility to take part in the second survey. This division of respondents pursued the goal of an unbiased assessment.

In addition, personal interviews were held among the members of the third group (persons not participating in the survey) on the associative array. In this case, the images from the first survey were offered to the respondents, on which they called their associations. The respondents were the students of all areas of training and forms of study of Kazan Federal University.

\section{Results and Discussion}

All results were mathematically processed. For this purpose, the normal law of distribution (Gaussian law) was used. 1. The results of surveys.

The following result was obtained for each question in the first survey: 


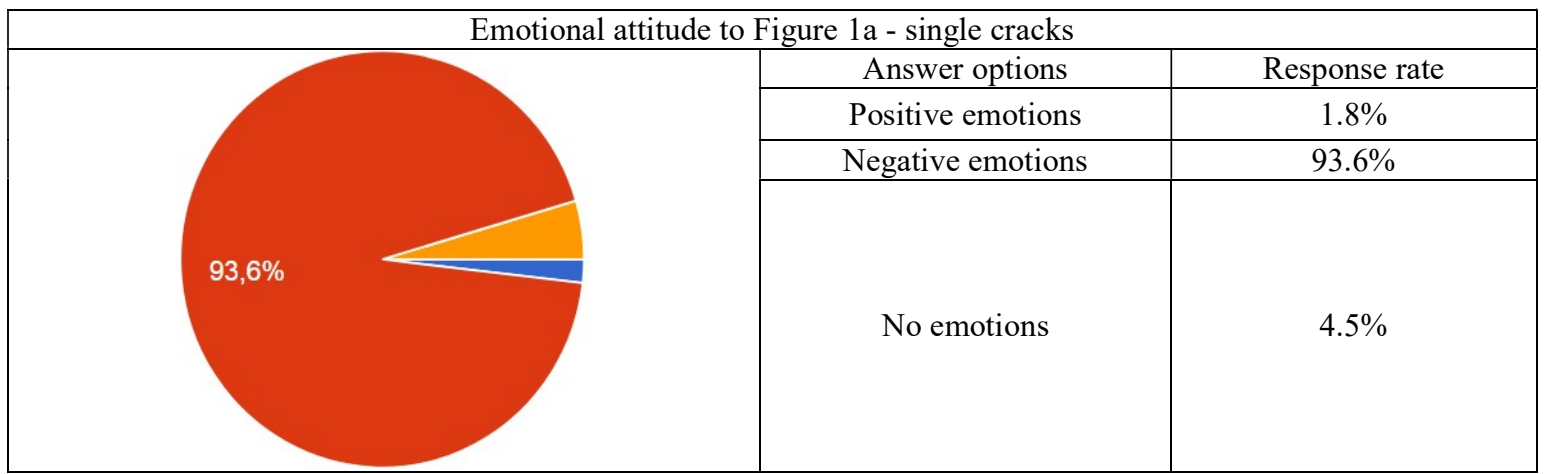

Table 1: Results for Figure 1a

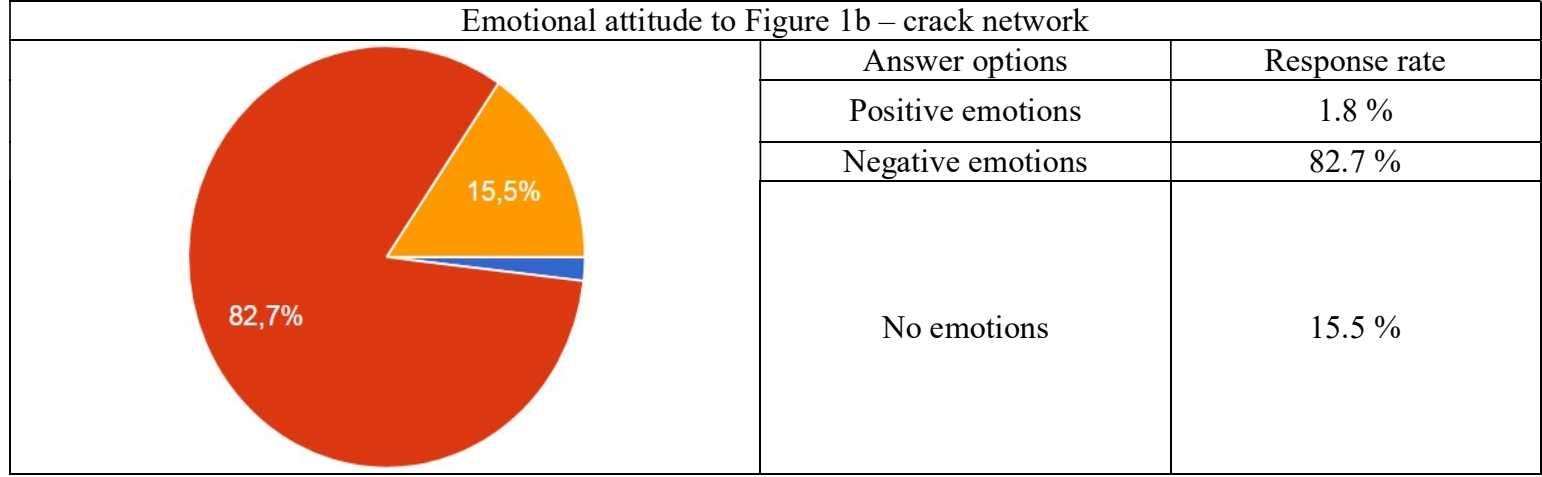

Table 2. Results for Figure 1b

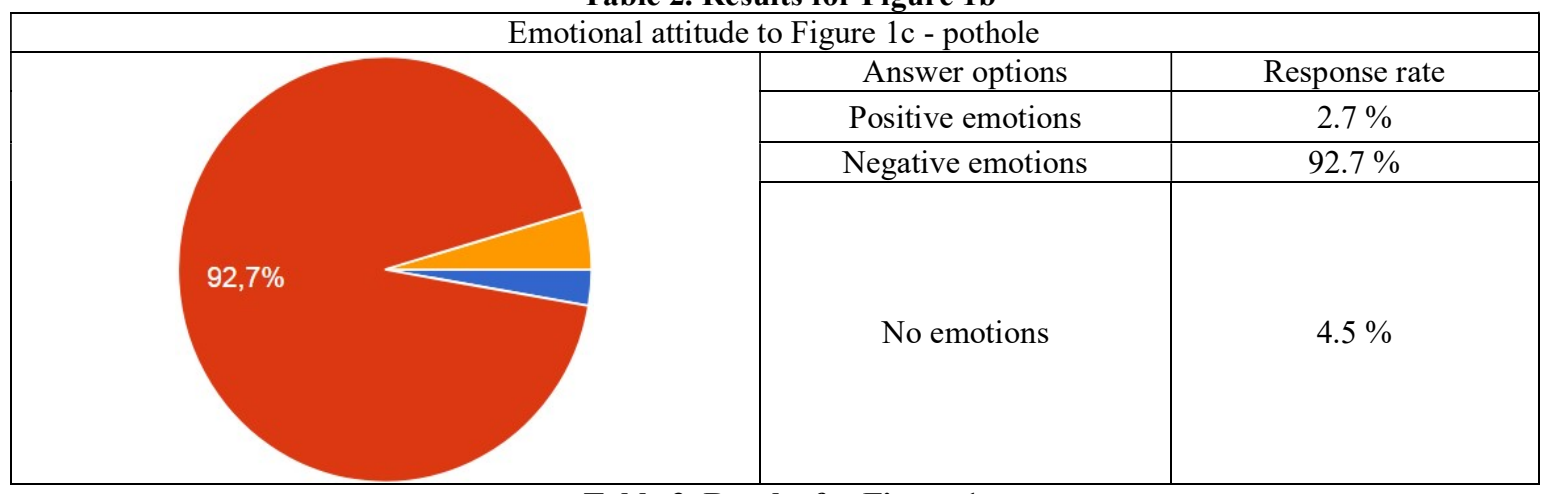

Table 3. Results for Figure 1c

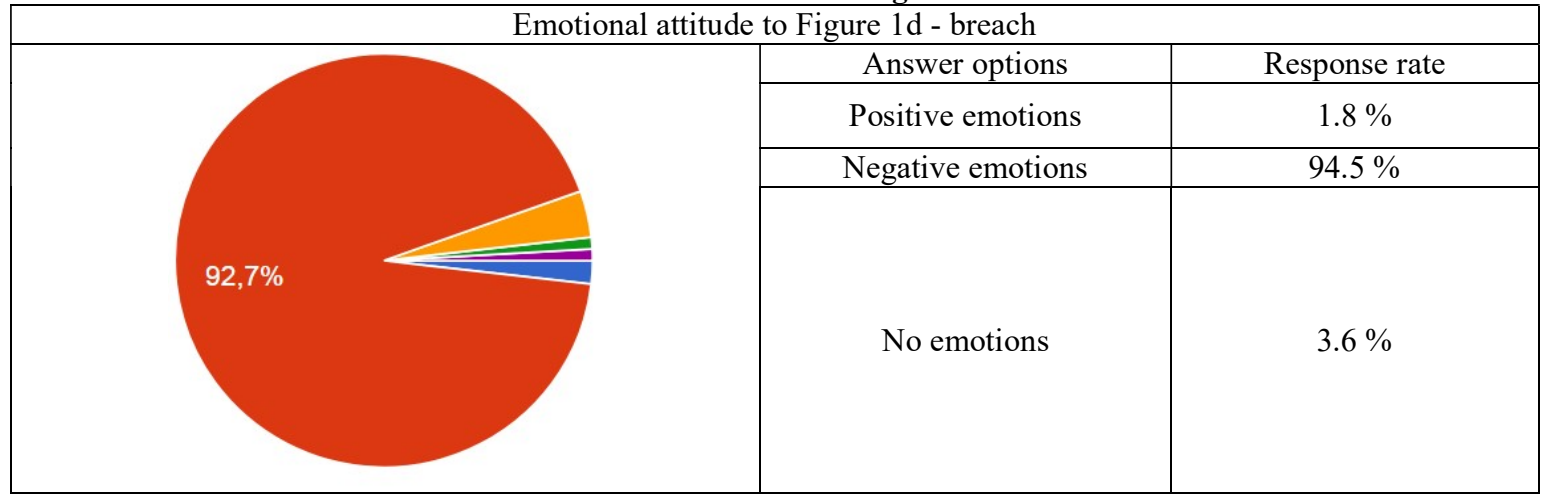

Table 4. Results for Figure 1d 


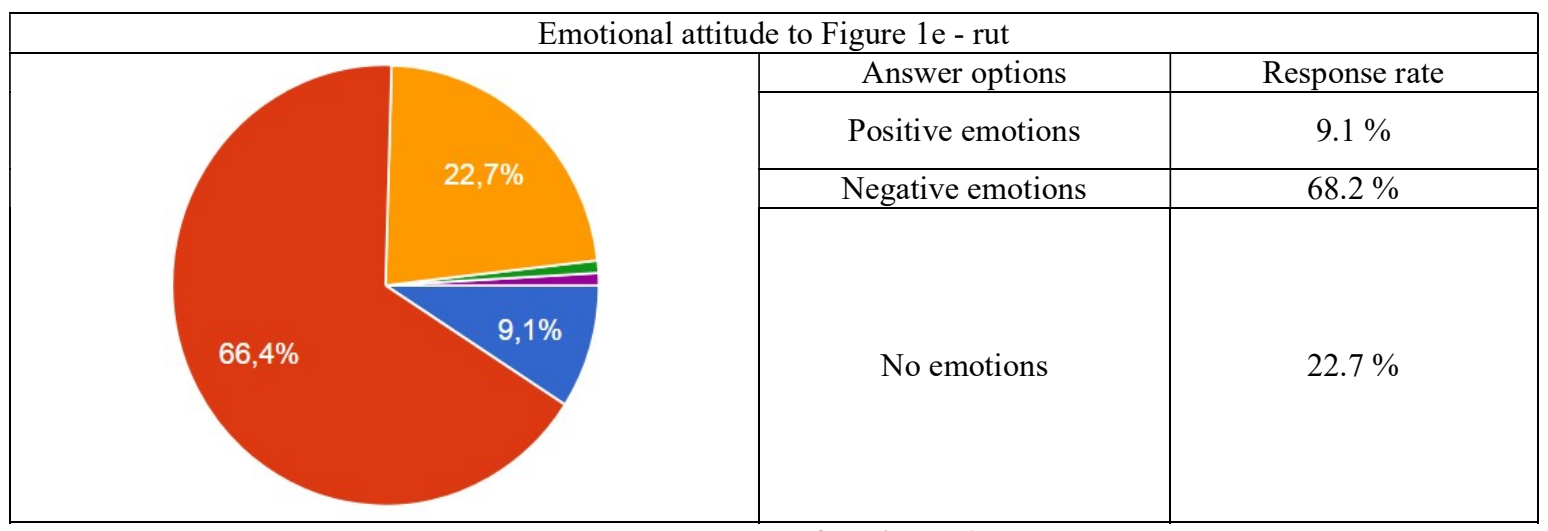

Table 5. Results for Figure 1e

Depending on the response, the option "alternative reply" is summed up with the similar ones.

The pie chart in table 4 shows that $92.7 \%$ of respondents evaluate the figure negatively, but the result in the table is $94.5 \%$. This is due to the fact, that $1.8 \%$ of respondents gave their own answers, namely "terrible" and "outrageous". These answers are negative, and thus they are summed up with the answer "negative emotions", hence $92.7 \%+$ $1.8 \%=94.5 \%$.

Table 6 presents the overall result for the entire second survey (for all images), since the difference between the answers is less than $5 \%$.

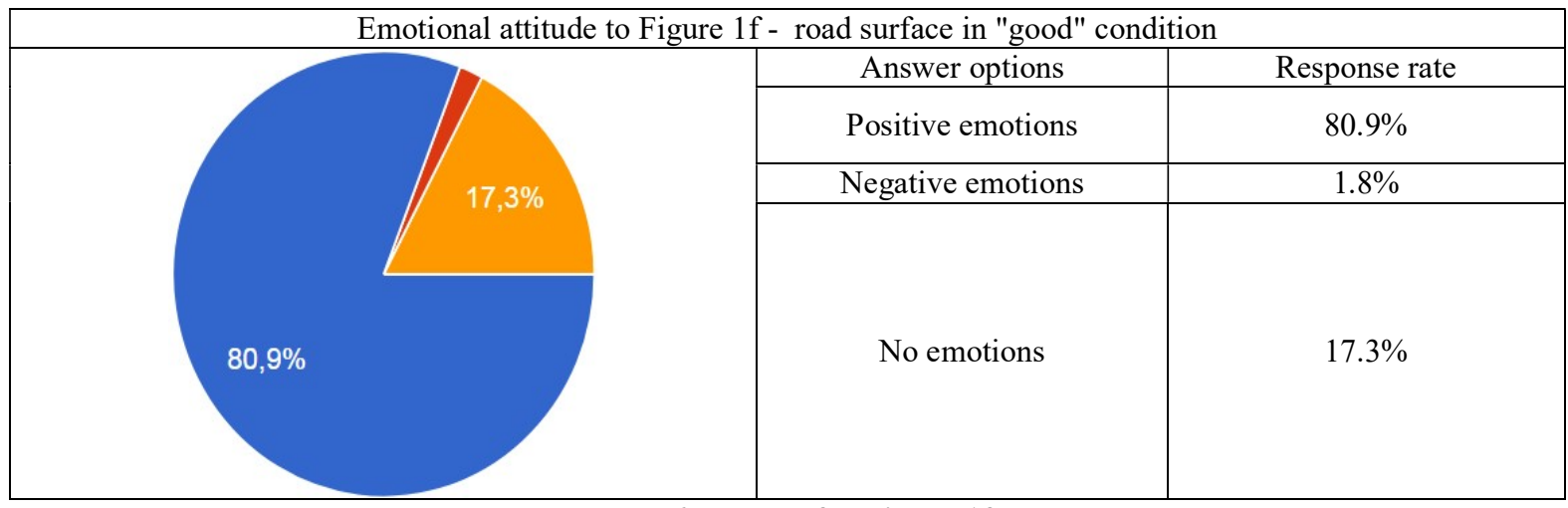

Table 6: Results for Figure 1f

The results of personal interviewing, using the association method.

The data, contained in table 7 in the column "Associations," were generalized and recorded in a compact form.

\begin{tabular}{|c|c|c|c|}
\hline Seq. No. & Figure number & Defect type & Associations \\
\hline 1 & 1a & Single cracks & poverty, lack, distress, deprivation. \\
\hline 2 & 1b & Crack network & old age, decrepitude, lack. \\
\hline 3 & 1c & Pothole & inferiority, pain, inferiority, deficiency. \\
\hline 4 & 1d & Breach & Ruteriority, pain, inferiority, deficiency. \\
\hline 5 & 1e & Rutirectionality, stiffness, dullness and hopelessness. \\
\hline 6 & 1f & $\begin{array}{c}\text { Road surface in } \\
\text { "good" condition }\end{array}$ & Path, road, highway, highway, uniformity, monotony. \\
\hline
\end{tabular}

Table 7: The Results of Personal Interviewing, Using the Association Method.

\section{Summary}

Based on the survey, carried out in the first group, where the respondents evaluated the images of some types of defects and damages of road surface, the following conclusions can be drawn:

1. negative attitude to all types of destruction and deformation ("negative emotions" were observed in $66.4 \%$ $93.6 \%$ of respondents);

2. the worse is the degree of visual destruction, the more negative answers are recorded; this can be seen in comparison with the same type of destruction, namely, "single cracks" - $93.6 \%$ of respondents have negative emotions, and "crack network" $-82.7 \%$ of respondents; 
3. the more severe is the damage, the less is the quantity of indifferent answers ("no emotions"), as a consequence of point 2.

Based on the survey, carried out in the second group, where the respondents evaluated the images of the road surface in "good" condition, the following conclusions can be drawn:

1. Overall positive attitude.

2. Compared with the first survey, there is a tendency for the increase in the number of neutral answers ("no emotions") by $41.27 \%$.

The purpose of these two surveys was to identify a common emotional evaluation.

Based on the personal interviewing, using the association method, we can draw the following conclusions:

1. the results of personal interviewing and two surveys, carried out using the images of roads, are similar in terms of emotional evaluation;

2. The majority of respondents draw an analogy with the road and their own lives.

If we consider all the participants in the survey and divide them into new groups, according to their location on the territory of the city, in places, where different conditions of the road surface are observed, we obtain the following results.

The respondents, living in places, where a significant part of roads has the defects and deformations, more vividly and more often give a positive or negative evaluation for the "good" road and the road with defects, respectively. And if we consider the respondents, who live in places, where the road surface is mostly in "good" condition, the number of positive and negative answers decreases, and there are more neutral answers ("no emotions").

So, the following conclusion can be made:

The decrease in the share of roads with defects leads to the neutralization of emotional evaluation.

Let's consider the mechanism of the influence of road surface condition on the worldview through the consciousness. The shaped worldview determines how a person will perceive the reality, as well as the direction of his general activity. General activity is a complex of physical and personal activity (purposefulness, motivation, emotional sensitivity).

Many factors are involved in shaping the worldview. Information and personal experience are the main among them. Through the information received, in the form of the road surface condition, personal experience is accumulated, which in turn shape the worldview.

Information should be often repeated in order to get deeper into the human consciousness. A person receives the main flow of information through the visual observation of surrounding reality.

Most often a person pays attention to the things, standing out from the general picture. This effect is related with the instinct of self-preservation - the search of food among vegetation of the same type (red apple against the background of green leaves), as well as the potential danger in the form of a predator, hiding in a forest or in tall grass.

Similarly, the defect on the surface, standing out against the general background of the roadway, accumulates in the mind. The greater is the number of various defects, the more information is received and, as a result, due to the large amount of data obtained, a personal worldview is shaped. Personal experience is also replenished through the tactile sensations, balance (shift of the center of gravity). When driving along a "good" road, with a smooth and even surface, the human consciousness practically does not perceive it. Consciousness is distracted by outside activity, since there is no need to perform additional actions, such as overstepping or bypassing the pothole and humps.

Personal worldview is strengthened and more deeply rooted in contact with the social worldview. If we take the results of the surveys, we will see that there is an accumulation of information, which carries mainly a negative character.

A person is surrounded by the modern infrastructure of the city and perceives the road as a part of the surrounding reality. But, if it is not possible to put the blame on climatic phenomena (precipitation in the form of rain and snow), then the responsibility for maintaining of public property in the normal state can be imposed on particular individuals, namely, on the repair and construction organizations.

Politicians in their speeches often talk about the improvement of road conditions [11]. These statements are supported by the strong interest of people in this matter.

\section{Conclusions}

Accumulated negative emotions can be manifested in the form of a disapproving attitude towards the workers of the road industry, who do not change the situation with the state of road surface, and towards the authorities, which do not use the levers of pressure to the responsible organizations.

The attitude of authorities towards the condition of road surface can be reflected in a decrease of the quality of human capital, that is equal to the loss of a valuable resource.

Maintenance of the good condition of automobile roads and walkways will result in a general neutral evaluation (a certain degree of social stability).

\section{Acknowledgements}

The work is performed according to the Russian Government Program of Competitive Growth of Kazan Federal University. 


\section{References}

1. Jung C. G. Two Essays on Analytical Psychology. Vol. 7| The collected works of C. G Jung. Second edition. Princeton University Press, 1966;

2. Jung C. G. Symbolical Life. Vol. 18 // The collected works of C. G Jung. Second edition. Princeton University Press, 1966.

3. Hegel: The Phenomenology of Spirit. Oxford University Press in the UK and in certain other countries. Michael Inwood 2018 ISBN 978-0-19-879062-4.

4. The Critique of Pure Reason by Immanuel Kant, trans. J. M. D. Meiklejohn, The Electronic Classics Series, Jim Manis, Editor, PSU-Hazleton, Hazleton, PA 18202. 2013.

5. Cole, M., \& Scribner, S. (Eds.). (1974). Culture and thought: A psychological introduction. New York: Wiley. Russian translation 1977.

6. A General Introduction to Psychoanalysis. Sigmund Freud. Translated by G. Stanley Hall. eBooks@Adelaide The University of Adelaide Library University of Adelaide South Australia 5005. URL: https://ebooks.adelaide.edu.au/f/freud/sigmund/general-introduction-to-psychoanalysis/index.html Last updated Sunday, March 27, 2016.

7. Roy Jenkins. Churchill: a biography. — Plume Books, 2002 - P: 1001 ISBN: 978-0452283527.

8. Wells, John. Rude Words: a discursive history of the London Library. — Macmillan, 1991. — ISBN 0333475194.

9. Rüdiger Safranski. Goethe. Kunstwerk des Lebens. Biographie.. — München: Hanser, 2013. — C. 32. — ISBN 978-3-446-23581-6.

10. English Aphorisms [Text] / S. A. Matveev. - Moscow: Astrel, 2012. - 253, [1] p. - Text parall. English, Russian. - ISBN 978-5-271-44974-1.

11. Here's Donald Trump's Presidential Announcement Speech (Engl.). Time.com (16.06.2015). Date of access: May 26, 2019. URL:http://time.com/3923128/donald-trump-announcement-speech/. 